\title{
Médiévales
}

Langues, Textes, Histoire

$64 \mid$ printemps 2013

Temporalités de l'Égypte

\section{Patrick GILLI et Julien THÉRY, Le Gouvernement pontifical et l'Italie des villes au temps de la théocratie (fin XII ${ }^{e}-m i-X I V^{e}$ siècle)}

Montpellier, Presses Universitaires de la Méditerranée, 2010, 676 p.

\section{Solal Abeles}

\section{(2) OpenEdition}

\section{Journals}

Édition électronique

URL : https://journals.openedition.org/medievales/7029

DOI : 10.4000/medievales.7029

ISSN : 1777-5892

Éditeur

Presses universitaires de Vincennes

\section{Édition imprimée}

Date de publication : 1 juillet 2013

Pagination : 190-193

ISBN : 978-2-84292-371-6

ISSN : 0751-2708

\section{Référence électronique}

Solal Abeles, « Patrick Gııı et Julien Théry, Le Gouvernement pontifical et l'Italie des villes au temps de la théocratie (fin xı $\|^{e}-m i-x v^{e}$ siècle) », Médiévales [En ligne], 64 I printemps 2013, mis en ligne le 09

septembre 2013, consulté le 24 avril 2022. URL : http://journals.openedition.org/medievales/7029 ; DOI : https://doi.org/10.4000/medievales.7029

Ce document a été généré automatiquement le 24 avril 2022.

Tous droits réservés 


\title{
Patrick GILLI et Julien THÉRY, Le Gouvernement pontifical et l'Italie des villes au temps de la théocratie (fin $\mathrm{XII}^{e}$ - mi-XIV siècle)
}

Montpellier, Presses Universitaires de la Méditerranée, 2010, 676 p.

\author{
Solal Abeles
}

«Schreiender Papst». Un pape qui trône et qui crie : telle est l'impression qui saisit le lecteur à l'orée de l'ouvrage de Patrick Gilli et Julien Théry. La reproduction en couverture d'une des célèbres variations de Francis Bacon autour du portrait d'Innocent X par Velázquez est en effet doublement bien choisie pour subsumer l'intention des auteurs, en ce qu'elle illustre aussi bien le propos général des textes rassemblés, traduits et présentés - donner à voir la geste italienne pontificale «au temps de la théocratie ", soit entre la fin du XII et le milieu du XIV siècle, et souligner ainsi le déploiement d'une souveraineté toujours plus ample - qu'elle permet de saisir immédiatement la singularité de la démarche éditoriale ici suivie. Car ce qui frappe en premier lieu à la lecture de ce beau livre, c'est justement le soin accordé à son édition. Les auteurs l'affirment d'emblée: l'un des objectifs est bien de mettre en valeur une série de textes, plus ou moins connus et étudiés, produits par la papauté, et non d'en livrer une simple et sèche mise à disposition. Ainsi de l'idée de mettre en regard sur chaque double page le texte original en latin et une traduction française méticuleusement pesée afin d'éviter l'écueil de l'illisibilité ou celui inverse de l'appauvrissement, dans un effort suffisamment rare pour être souligné. Ainsi également de l'organisation des textes en treize dossiers dotés chacun d'une brève présentation et regroupés à leur tour dans quatre grands axes thématiques. Ainsi, enfin, de la richesse de l'index, composé non seulement des noms propres, mais aussi des citations juridiques et même des "citations et réminiscences bibliques ", qui sont par ailleurs données in extenso en notes à la fin de chaque dossier. Ce dense apparat trouve en fin de compte sa justification même dans les spécificités de la prose 
pontificale. C'est à ce prix, ainsi que le rappellent Julien Théry et Patrick Gilli, que l'on peut espérer mieux en saisir l'une des caractéristiques principales: l'intertextualité, qui confère aux « dits et écrits » des papes leur complexité sémantique et renforce de ce fait la puissance de leur rhétorique.

Un projet éditorial, aussi riche et soigné soit-il, n'a toutefois d'utilité véritable que s'il permet d'offrir un éclairage nouveau. Les auteurs ont donc mis leur érudition au service d'un but précis: (r)ouvrir une réflexion autour de la politique pontificale à l'égard des communes italiennes, et tenter de relever le défi d'une histoire commune aux deux entités. Car si la papauté entend ordonner de plus en plus fermement l'Occident tout entier, l'Italie communale occupe dans ce programme une place particulière, moins pour une proximité géographique évidente que pour des raisons plus complexes. Trois caractères particuliers du contexte communal italien sont ainsi bien rappelés: l'opposition radicale entre deux types de pouvoirs (gouvernement collectif aux fondements juridiques incertains d'un côté, autocratie spirituelle aux visées toujours plus temporelles de l'autre) qui n'ont en commun qu'une nature profondément innovante ; l'existence de zones en Italie centrale sur lesquelles le pape revendiquait, au nom du Patrimoine de saint Pierre, une entière souveraineté qu'il entendait imposer aux communes locales ; l'affrontement avec l'Empereur dont l'Italie centro-septentrionale fut le principal théâtre, et les communes des acteurs incontournables. Ces trois thèmes constituent les grands axes du livre, auxquels s'en adjoint un quatrième centré sur la pratique inquisitoriale.

3 La «Lutte contre l'Empire et politique italienne » (chap. 1) reste sans nul doute le point le plus évident d'une réflexion sur les rapports entre le pape et les communes, tant celles-ci furent directement concernées par les velléités impériales. Mais en sus d'épisodes bien connus, d'autres aspects moins attendus sont mis en lumière. On pense en particulier à l'ensemble de documents qui renvoient à l'intense action pontificale mise en œuvre immédiatement après la mort de Manfred en 1266 et l'effondrement consécutif de la puissance impériale. Si la série de légations pontificales rondement menées permet ainsi, dès 1267, de faire basculer du côté du pape les cités lombardes traditionnellement les plus hostiles (principalement Crémone et Plaisance), c'est à Florence que l'effort papal est le plus intense. L'action pacificatrice menée par Clément IV (1265-1268), puis surtout Grégoire X (1271-1276), semble de fait essentielle parce qu'elle permet de réguler au moins temporairement une forte conflictualité interne, tout en posant les bases d'une alliance entre la cité toscane et la papauté qui devint dès lors une des constantes de l'histoire politique italienne.

En parallèle à l'œuvre anti-impériale du souverain pontife à vocation universelle et totalisante, son intervention dans la vie communale est également justifiée par sa position éminente dans la hiérarchie ecclésiastique. Ainsi la seconde partie de l'ouvrage («Papauté, communes urbaines et églises locales») propose-t-elle une série de documents qui rappellent combien le contrôle du clergé communal constitue un point d'achoppement des relations entre la papauté et les cités italiennes. La question est en premier lieu d'ordre fiscal : contre les communes qui tentent d'imposer au clergé local une participation financière, la réaction pontificale, telle qu'on la perçoit à travers quatre lettres envoyées par Innocent III aux communes lombardes, ne se fait pas attendre : remettre en cause l'exemption fiscale dont jouissent traditionnellement les clercs, c'est attenter à l'un des noyaux de l'autonomie ecclésiale. Innocent III en profite par ailleurs pour poser les bases d'une innovation juridique définitivement adoptée lors 
$\mathrm{du}$ Concile de Latran IV. Non seulement les officiers responsables de ces mesures hostiles doivent être excommuniés, mais la sanction touchera désormais également la fonction même et non plus uniquement les hommes. Nouveauté importante car elle permet d'atteindre le cœur du système politique communal, dont la rotation rapide des charges et des hommes constitue l'un des pivots.

De la fiscalité à la " religion civique ", il n'y a qu'un pas, que les textes nous permettent de franchir aisément. Car si les questions sont ici plus symboliques que matérielles, l'enjeu est peu ou prou similaire, soit la volonté de la part des autorités communales de récupérer une part de la puissance ecclésiale. Face à ces velléités, les réactions pontificales sont plus nuancées, et parfois même bienveillantes, dès lors que les demandes communales ne menacent pas le monopole ecclésiastique. C'est le cas de la canonisation d'Antoine de Padoue en 1232: la célérité extrême de la procédure (entérinée un an à peine après la mort du frère prêcheur) doit moins aux demandes pressantes des Padouans qu'à la volonté de Grégoire IX de faire de cette canonisation un instrument de lutte contre l'hérésie. A contrario, la croissance des confraternités laïques romaines est bloquée par le même Grégoire IX car ces associations échappent en partie au contrôle clérical. On comprend mieux, par ailleurs, le rôle décisif joué par la fonction épiscopale comme intermédiaire entre la papauté et les communes, mais l'un des grands mérites de certains textes ici rassemblés est de mettre en avant un véritable processus de disciplinement des évêques sous la bannière pontificale. Ceux-ci font ainsi l'objet d'un contrôle toujours plus strict, par la généralisation de la réserve des bénéfices majeurs, mais également à travers l'élaboration de la notion de " pouvoir de juridiction» conféré non plus directement par Dieu, mais bien par le pontife luimême. L'évolution de la titulature en marque une forme d'aboutissement : à partir du début du XIV $v^{e}$ siècle, la fonction épiscopale est désormais tenue "par la grâce de Dieu ", mais aussi, fait nouveau, «par celle du Siège apostolique ».

Dans la troisième partie («La papauté et les villes des États pontificaux »), l'autorité du pape ne connaît guère de limites, qu'il s'agisse d'arbitrer des conflits internes, comme à Pérouse au début du XIII ${ }^{e}$ siècle, ou de mettre en place un système efficace de gouvernement par l'intermédiaire de recteurs pontificaux et de mesures constitutionnelles, judiciaires et fiscales, comme dans le Duché de Spolète au mitan du $\mathrm{XIV}^{\mathrm{e}}$ siècle. Relevons également une tentative aussi éphémère qu'importante d'étendre la domination au-delà du Patrimoine, avec la brève soumission dans les années 1330 de Plaisance, pourtant située au cœur de l'État milanais. Cas passionnant, qui démontre que le système complexe et encore mal connu de la « dédition » d'une communauté à un pouvoir supérieur, qu'il soit urbain, monarchique ou impérial, concerne aussi l'État pontifical.

7 La dernière partie de l'ouvrage («Théocratie, hérésie, inquisition ») démontre combien l'élaboration d'un arsenal répressif pour lutter contre l'hérésie constitue l'une des facettes de l'interventionnisme pontifical dans la vie communale. Comme le rappellent très justement les auteurs, "on comprendrait mal l'ampleur de la lutte contre la supposée hérésie si l'on ignorait l'arrière-plan communal qui en est le véritable moteur ». La norme inquisitoriale, fixée durant la première moitié du XIII siècle, ressortit en fait davantage à un enjeu politique qu'à des questions strictement doctrinales et techniques. Ainsi de la bulle Ad extirpanda adressée en 1252 aux cités lombardes, surtout connue pour contenir comme la première légalisation explicite de l'usage de la torture, alors que son objectif principal est bien de placer l'action des 
gouvernants communaux sous la dépendance stricte des tribunaux inquisitoriaux. Objectif poursuivi également à travers l'injonction adressée aux inquisiteurs d'Italie du Nord, sommés à la même époque de soumettre le droit statutaire local aux décrétales pontificales, sous couvert encore une fois d'intensification de l'hérésie. Les auteurs soulignent ainsi que l'« on comprendrait mal l'ampleur de la lutte contre la supposée hérésie si l'on ignorait l'arrière-plan communal qui en est le véritable moteur: domestiquer les communes, les soumettre à l'ordre romain, [...] tel est l'enjeu fondamental de la définition du crime d'hérésie et des innovations judiciaires qui en ont résulté » (p. 596).

En fin de compte, c'est bien la question de la gouvernementalité pontificale qui est au cœur de l'ouvrage. Tenter, autrement dit, de comprendre comment un pouvoir qui, cas peut-être unique dans l'histoire occidentale, ne dispose d'aucune ressource militaire propre, parvient tout de même à construire et à affirmer son autorité sur d'autres entités politiques. Et c'est au prisme de cette question que la démarche des auteurs prend tout son sens: proposer un accès aussi clair à un ensemble de documents produits par les papes afin d'appréhender la richesse et la puissance proprement performative de la rhétorique pontificale comme un instrument essentiel de domination; poser d'autre part les bases d'une histoire conjointe de la papauté et des communes italiennes, qui reste encore presque tout entière à écrire. 